\title{
Oceanographic Responses to Climate in the Northwest Atlantic
}

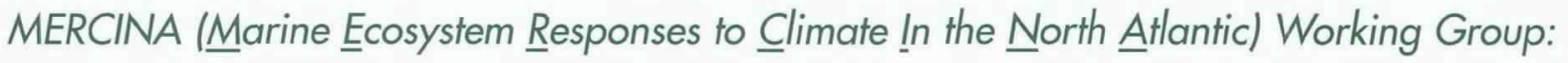

\author{
Andrew J. Pershing*, Charles H. Greene* \\ Cornell University . Ithaca, New York USA
}

Charles Hannah, Doug Sameoto, Erica Head

Bedford Institute of Oceanography. Dartmouth, Nova Scotia Canada

David G. Mountain

National Marine Fisheries Service. Woods Hole, Massachusetts USA

Jack W. Jossi

National Marine Fisheries Service. Narragansett, Rhode Island USA

Mark C. Benfield
Lovisiana State University • Baton Rouge, Lovisiana USA

Philip C. Reid

Sir Alister Hardy Foundation for Ocean Science. Plymouth United Kingdom

Ted G. Durbin

University of Rhode Island. Narragansett, Rhode Island USA

\begin{abstract}
Situated in an oceanographic transition zone, the Gulf of Maine/Western Scotian Shelf (GOM/WSS) region of the Northwest Atlantic is especially susceptible to changes in the climate system. Recent studies have shown that a coupled slope water system (CSWS) operates in the Northwest Atlantic and responds in a similar manner to climatic forcing over a broad range of time scales. These studies further suggest that it may be possible to associate different modes of the CSWS with different phases of the North Atlantic Oscillation (NAO). Results from recent GLOBEC field studies in the Northwest Atlantic provide strong evidence linking physical responses of the CSWS to basin-scale forcing associated with the NAO. By placing these results in the context of time-series data collected from the GOM/WSS region over the past half century, we show that: (i) the region's shelf ecosystems respond both physically and biologically to modal shifts in the CSWS; (ii) the CSWS mediates
\end{abstract}

the effects on these ecosystems of basin-scale climatic forcing associated with the NAO; and (iii) certain planktonic species can be good indicators of the CSWS's modal state on interannual to interdecadal time scales.

The ecological geography of the sea is determined by the dynamic interplay of ocean physics and biology (Longhurst, 1998). Distinctive biogeographic provinces have been identified throughout the world's oceans, and frequently these exhibit considerable overlap with recognized hydrographic domains. Situated between such biogeographic provinces are the oceanographic transition zones, regions where flora, fauna, and water masses mix to produce assemblages of organisms and environmental conditions that can take on highly dynamic characters of their own. It is these oceanographic transition zones that expand, contract, and shift position in response to the different rhythms of cli-

* Andrew J. Pershing and Charles Hannah are the lead authors and contributed equally to this article. 


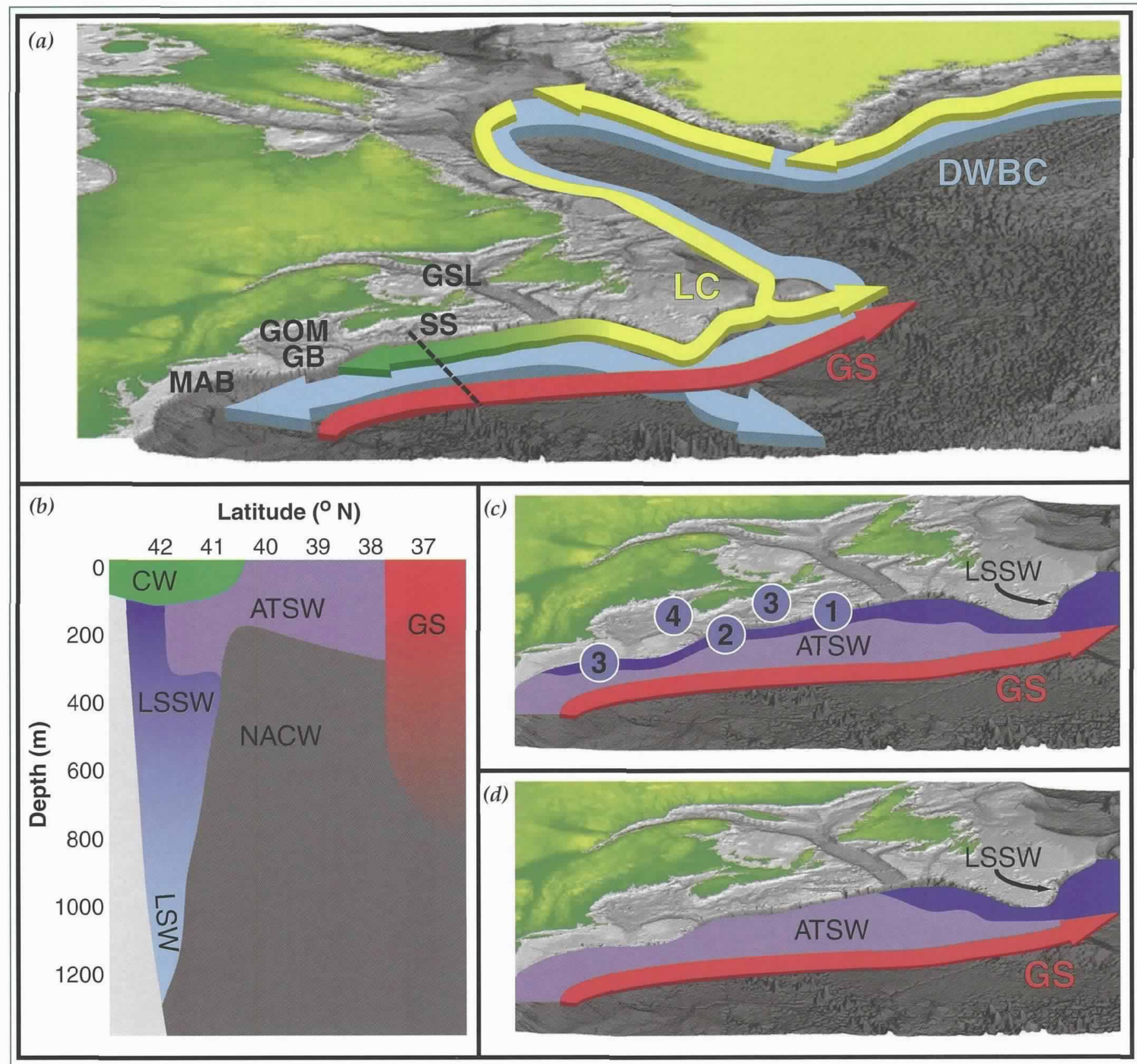

\section{Figure 1.}

(a) Circulation patterns of the Northwest Atlantic focusing on the CSWS. Hydrographic section shown in Figure $1 b$ is indicated by dashed line. (b) Hydrographic section through the CSWS. (c) Minimum modal state of the CSWS. Circled numbers indicate 1997-98 advance of LSSW frontal boundary along continental margin: 1-September 1997, 2-January 1998, 3-February 1998, 4-August 1998. (d) Maximum modal state of the CSWS. Geographical features, water masses, and currents are labeled as follows: Georges Bank = GB, Gulf of Maine $=$ GOM, Gulf of St. Lawrence $=$ GSL, Middle Atlantic Bight $=$ MAB, Scotian Shelf $=$ SS, Atlantic Temperate Slope Water $=$ ATSW, Coastal Water $=$ CW, Labrador Sea Water $=$ LSW, Labrador Subarctic Slope Water $=$ LSSW, North Atlantic Central Water $=$ NACW, Deep Western Boundary Current $=$ DWBC, Gulf Stream $=$ GS, Labrador Current $=L C$. 


\section{Box 1 \\ Indices of Climatic and Oceanographic Conditions}

The NAO Index is the mean winter-time atmospheric pressure difference anomaly between the North Atlantic's subtropical high pressure system, measured in Lisbon, Portugal, and subpolar low pressure system, measured in Stykkisholmur, lceland (Hurrell, 1995).

\section{The Regional Slope Water Temperature} Index was developed as an indicator of the modal state of the CSWS, with positive (negative) values corresponding to maximum (minimum) modal state conditions. It is the dominant mode derived from a principal components analysis of 8 slope water temperature anomaly time series from the GOM/WSS region. The time series correspond to mean annual slope water temperature anomalies between 150-250 $\mathrm{m}$ in Emerald Basin, Georges Basin, Jordan Basin, Wilkinson Basin, and from four geographic sectors overlying the region's continental slope.

The Calanus finmarchicus Abundance Index is the mean abundance anomaly for this species calculated each year as the mean difference between log-transformed observed abundances and log-transformed expected abundances. Expected abundances were determined from the climatological mean seasonal cycle of $C$. finmarchicus in the Gulf of Maine. Abundance data were derived from Continuous Plankton Recorder surveys conducted in the GOM/WSS region since 1961 (Jossi and Goulet, 1993). Only data for late copepodites and adults were included in the time series.

mate variability. In the North Atlantic Ocean, the dominant interannual to interdecadal rhythms of climate variability are associated with the North Atlantic Oscillation (NAO). Here, we present a synthesis of current ideas linking ecosystem changes in the Gulf of Maine/Western
Scotian Shelf (GOM/WSS) region to modal shifts in ocean circulation associated with the NAO.

The GOM/WSS region of the Northwest Atlantic is located near the terminal end of the Labrador Current, a large buoyancy-driven coastal current system extending from the west coast of Greenland to the Middle Atlantic Bight (Figure 1a) (Chapman and Beardsley, 1989). To the south and east, the region is bordered by the Middle Atlantic Bight, Georges Bank, and the Slope Water Sea overlying the continental slope. This location places it within a shifting transition zone between cold subpolar waters, influenced by fluctuations in the Labrador Current to the northeast, and warm temperate waters, influenced by fluctuations in the Gulf Stream to the south (Loder et al., 2001). The transitions that occur within this zone are not only physical, as reflected in hydrographic changes, but also biological, as reflected in the changes in composition and relative abundance of plankton. The shifting nature of this transition zone has made the GOM/WSS region a special focus of global climate change research in the Northwest Atlantic (GLOBEC, 1991).

Recently, it has become apparent that the upper slope waters (shallower than $800 \mathrm{~m}$ ) play a critical role in mediating the effects of climate change on the shelf ecosystems of the GOM/WSS region (Marsh et al., 1999; Greene and Pershing, 2000). There are two principal types of slope water affecting the region, Atlantic Temperate Slope Water (ATSW) and Labrador Subarctic Slope Water ${ }^{1}$ (LSSW) (Figure 1b). The relatively warm and salty ATSW is a mixture of Coastal and Gulf Stream Water situated in the upper $400 \mathrm{~m}$ of the water column. LSSW is a cooler and fresher mixture of Labrador Current Water and North Atlantic Central Water situated below $100 \mathrm{~m}$ along the upper continental slope. In hydrographic sections where they cooccur, ATSW lies further offshore, located between the Gulf Stream on the oceanic side and the shallower Coastal Water and deeper LSSW on the continental margin side (Figure 1b).

These upper slope waters have been shown to respond as part of a coupled system to basin-scale changes in climate operating on interannual to millennial time scales (Keigwin and Pickart, 1999; Pickart et al., 1999; Loder et al., 2001). Pickart et al. (1999) have identified two characteristic modes for the Northwest Atlantic's Coupled Slope Water System (CSWS). The minimum mode corresponds to a state in which southwestward transports of the Labrador Current and LSSW are intensified, while hydrographic signatures of Labrador Sea Water in the Deep Western Boundary Current are reduced. The enhanced volume transports of the Labrador Current and LSSW during this minimum mode result in these cooler, fresher waters advancing further downstream than usual along the continental margin, displacing the warmer, saltier

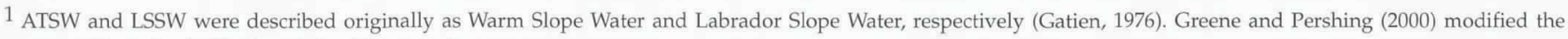
nomenclature to clarify the origin of these water masses. 
ATSW further offshore (Figure 1c). The maximum mode of the CSWS corresponds to a state in which hydrographic signatures of Labrador Sea Water in the Deep Western Boundary Current are enhanced, while southwestward transports of the Labrador Current and LSSW are reduced (Figure 1d). The reduced volume transports of the Labrador Current and LSSW during this maximum mode result in the frontal boundary of this water mass retreating upstream along the continental margin, allowing ATSW to move onshore towards the shelf.

Pickart et al. (1999) suggest that, although the linkage is not straightforward, it is tempting to associate maximum (minimum) modes of the CSWS with positive (negative) phases of the NAO. Findings from recent GLOBEC field studies in the Northwest Atlantic provide strong evidence for such an association. From the early to mid-1990s, the NAO Index (Box 1) was in a strongly positive phase, with the CSWS in its corresponding maximum modal state (Pickart et al., 1999). During the winter of 1996, the NAO Index exhibited its largest single-year drop of the twentieth century, attaining a negative value not seen since the 1960s. This dramatic drop in the NAO Index was followed by a modal shift in the CSWS, with the Labrador Current intensifying and the LSSW steadily advancing along the shelf break, displacing ATSW offshore, and penetrating to the southwest as far as the Middle Atlantic Bight (Figure 1c) (Drinkwater et al., in press).

In addition to its southwestward advance along the shelf break, the LSSW also made extensive incursions into the deep basins of the GOM/WSS region (Figure 2) (Drinkwater et al., in press). Although located on the continental shelf, these deep basins contain large quantities of slope water derived from off the shelf (Brown and Irish, 1993; Petrie and Drinkwater, 1993). From the 1970s until 1997, the deep waters of these basins were relatively warm and salty, reflecting their ATSW origin. By the early winter of 1998, LSSW had replaced the deep waters of Emerald Basin on the WSS and began entering the GOM through Northeast Channel. This relatively cool, fresh LSSW continued to advance through the deeper regions of the GOM, replacing the deep waters of Georges Basin by the spring of 1998. By the early autumn of 1998, the hydrographic properties of the deep waters in Jordan Basin and Wilkinson Basin

(b)
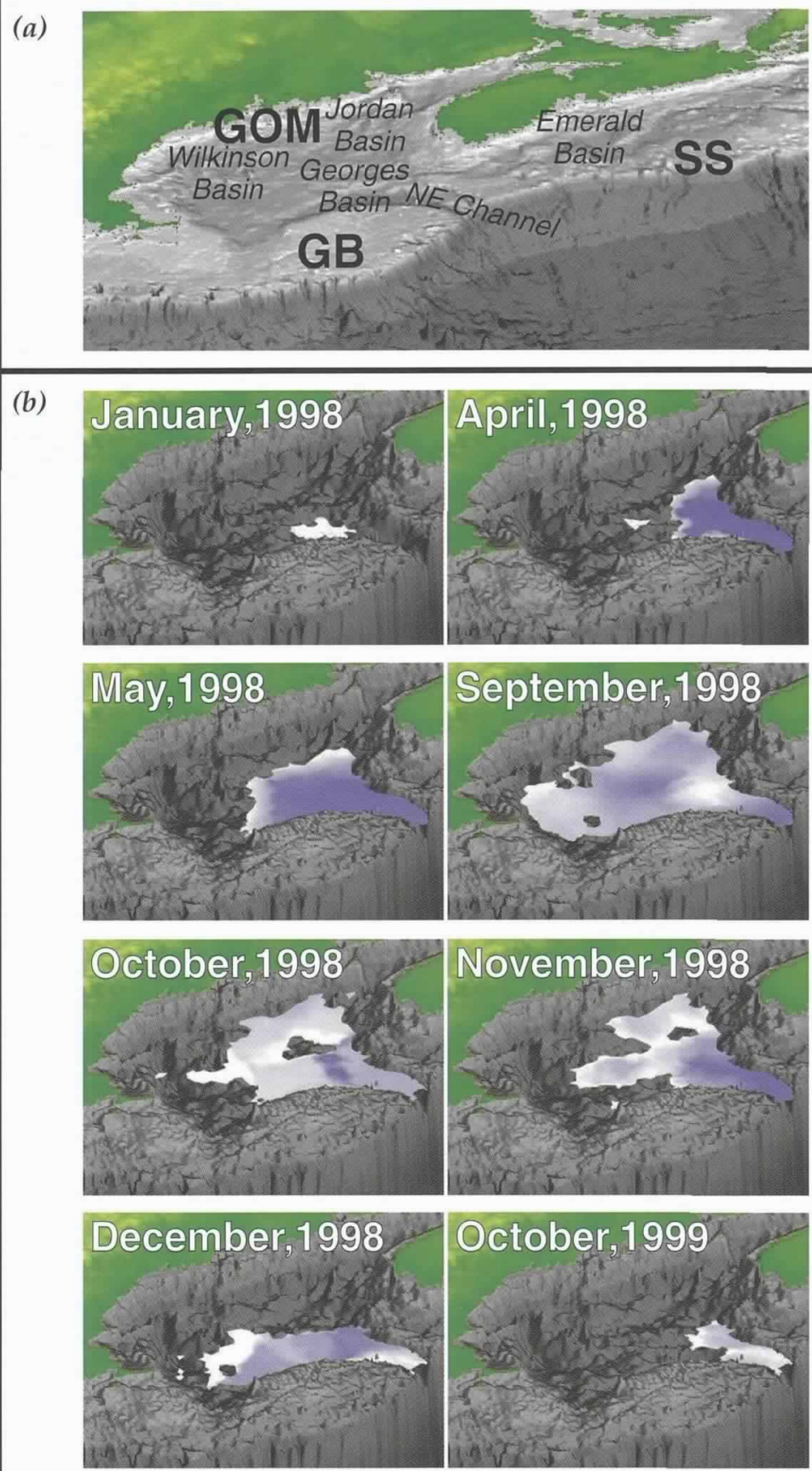

Figure 2. (a) The GOM/WSS region. (b) The intrusion and subsequent replacement of LSSW in the deep basins of the GOM from January 1998 through October 1999. Percent composition of LSSW in deep waters are indicated in shades of blue, with the lightest shade corresponding to $20 \%$ LSSW and the darkest shade corresponding to 100\% LSSW. 
was a single-year event, and the Index returned to positive values for the remainder of the 1990s. Likewise, the CSWS shifted back to its maximum modal state, with the Labrador Current weakening and the frontal boundary of the LSSW retreating northeastward along the Scotian Shelf (Drinkwater et al., in press). As the supply of LSSW to the region decreased, ATSW returned to its previous position adjacent to the shelf break and began supplying warmer, saltier slope water to Emerald Basin. By the spring of 1999, the deep waters of Emerald Basin were once again relatively warm and salty, reflecting their ATSW origin. Similarly, the hydrographic signatures of LSSW in the deep basin waters of the GOM were steadily lost through advective replacement and mixing, principally with ATSW entering through Northeast Channel. By the end of 1999, the hydrographic conditions in the GOM deep basins resembled those prior to the modal shift in the CSWS triggered by the 1996 drop in the NAO Index (Figure 2).

The oceanographic events observed in the Northwest Atlantic during the latter part of the 1990s provide circumstantial evidence that the NAO can alter hydrographic conditions in the shelf ecosystems of the GOM/WSS region and that these effects are mediated by modal shifts in the CSWS. To generalize from these observations, we now place them in the context of physical and biological time-series data collected from the GOM/WSS region over the past half century (Figure 3).

From 1950 to 1999, the NAO Index exhibited considerable interannual variability (Figure 3a). Against this background of interannual variability in the time series, two longer term patterns are apparent. During the decade of the 1960s, the NAO Index was in a predominantly negative phase, while during the subsequent three decades, it was in a predominantly positive phase. During the three decades of predominantly pos-

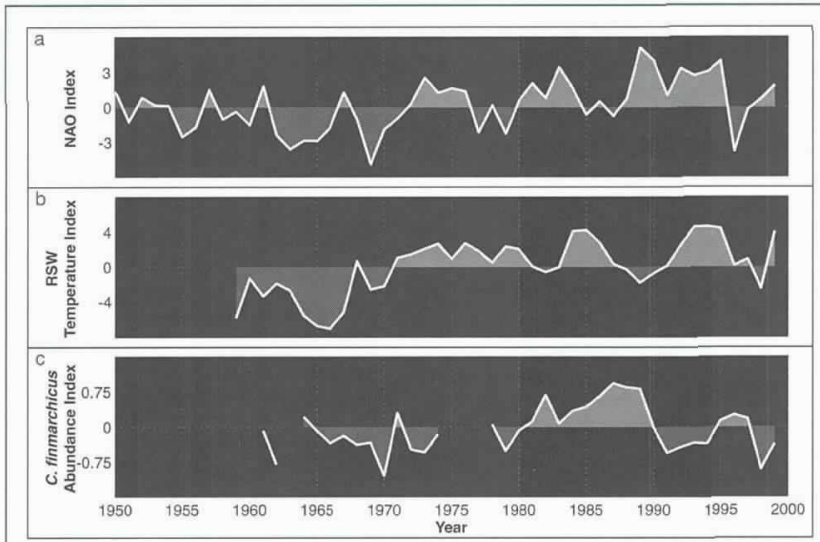

Figure 3. Time series from the North Atlantic. (a)Annual values of the winter NAO Index. (b) Annual values of the RSW Temperature Index. (c) Annual values of the Calanus finmarchicus Abundance Index.

\section{Box 2}

\section{Cross-Correlation Analyses of Time Series}

Cross-correlation analyses of the NAO Index and Regional Slope Water Temperature Index time series were conducted in a stepwise manner. Without detrending and prewhitening the time series, significant correlations were found with a range of time lags from $0-4$ years. After detrending the time series, a significant correlation was only found with a time lag of one year, although the correlation with a time lag of two years was nearly significant. After detrending the time series and pre-whitening them to remove significant autocorrelations, the correlation with a time lag of one year remained significant $\left(r^{2}=0.31 ; p<0.05\right)$, but the correlation with a time lag of two years became less significant. Despite the two-year time lag's lack of significance in the more conservative analyses, we have chosen to interpret the time lag as variable and ranging from 1-2 years. We believe that this interpretation is justified for two reasons. First, the discrete nature of the annual values making up each of the time series reduces our ability to resolve time lags falling between one and two years. Second, the time series are relatively short, limiting our ability to detect significant correlations that might emerge from longer time series.

Cross-correlation analyses of the Regional Slope Water Temperature Index and the Calanus finmarchicus Abundance Index also were conducted in a stepwise manner.

Without detrending and pre-whitening the time series, significant correlations were found with time lags ranging from 1-7 years. After detrending the time series, significant correlations were found with time lags ranging from 2-4 years. Finally, after detrending the time series and pre-whitening them to remove significant autocorrelations, a significant correlation was only found with a time lag of three years $\left(r^{2}=0.25 ; p<0.05\right)$. From these results, we have chosen to interpret the time lag as variable and centered on three years. 
itive values, the NAO Index dropped to negative values on five occasions $(1977,1979,1985,1987,1996)$, and each of these shifts was for only a year. Among the five single-year drops in the NAO Index after the 1960s, only the one that occurred in 1996 stands out as an extreme event in the time series.

During the same 50-year period, a time series of the Regional Slope Water (RSW) Temperature Index (Box 1) indicates that the CSWS has existed predominantly in its maximum modal state (Figure 3b). The only extended period during this interval in which the CSWS existed in its minimum modal state occurred during the decade of the 1960s. After the 1960s, the CSWS appears to have shifted from its maximum to minimum modal state on only a few brief occasions during the early 1980s, late 1980s and late 1990s.

From both 50-year records, we suggest that it is reasonable to associate positive (negative) phases of the NAO with maximum (minimum) modes of the CSWS. The decade-long negative phase of the NAO observed during the 1960s coincided with the only extended period in the record during which the CSWS existed in its minimum modal state. When the NAO shifted from a predominantly negative to a predominantly positive phase for the subsequent three decades, the CSWS also shifted to a predominantly maximum modal state.

While longer term phase changes in the NAO are positively associated with shifts in the CSWS's modal state, the relationship between the two is less clear on shorter time scales. The NAO Index and RSW Temperature Index are significantly correlated, but the time lag appears to be variable, with slope water temperature responses lagging changes in the NAO by one to two years (Box 2). This finding is consistent with the response of the RSW Temperature Index to the extreme, single-year drop of the NAO Index in 1996. It is also consistent with linking the weaker modal shifts in the CSWS observed during the early and late 1990s to changes from positive to negative values of the NAO Index in 1979 and 1987, respectively. Given the variable nature of the time lag, however, we do not feel that the evidence is strong enough to exclude the possibility that other non-NAO associated changes in the climate system may have triggered these weaker modal shifts in the CSWS.

Although we have provided evidence that the GOM/WSS's regional hydrography responds to climate-driven changes in the CSWS, this raises the question of whether or not there are biological correlates to this physical response. A time series of the Calanus finmarchicus Abundance Index (Box 1) from the GOM provides evidence for such a biological response (Figure 3c). C. finmarchicus is a calanoid copepod species that dominates the springtime zooplankton biomass and secondary production in the GOM/WSS region. With a variable time lag centered on three years, the $C$. finmarchicus Abundance Index is significantly correlated with the RSW Temperature Index (Box 2). During the decade of the 1960s, when the NAO Index was predominantly negative and the CSWS was in its minimum modal state, slope water temperatures and C. finmarchicus abundance were relatively low. During the 1980s, when the NAO Index was predominantly positive and the CSWS was predominantly in its maximum modal state, slope water temperatures and C. finmarchicus abundance were relatively high. During each of the maximum to minimum modal shifts in the CSWS after 1980, C. finmarchicus abundance declined in subsequent years. The modal shift during the early 1980 s preceded a large, single-year decline in abundance during 1983 . The modal shift during the late 1980 s preceded a large decline in abundance that persisted throughout the early 1990s. Then, after $C$. finmarchicus abundance began building up again during the mid1990s, the NAO Index underwent its drop of the century during 1996. This event triggered the intense modal shift of the CSWS during the late 1990s, which, in turn, led to very low abundances of $C$. finmarchicus during 1998.

The fact that $C$. finmarchicus is such a good indicator of climate-driven changes in the CSWS should not be too surprising. Although C. finmarchicus dominates the springtime zooplankton biomass and secondary production in the GOM/WSS region, it is an expatriate species in these ecosystems whose populations must be replenished every year or every few years by advection from some external source (Longhurst, 1998; Miller et al., 1998; Greene and Pershing, 2000). Among potential sources, the slope water is the most proximate. Even if the supply of $C$. finmarchicus to shelf ecosystems in the GOM/WSS region is ultimately derived from elsewhere, it is likely that most copepodites recruiting to these ecosystems from oceanic waters pass through the CSWS on their way to the shelf. Although we cannot document the detailed physical and biological mechanisms yet, we hypothesize that $C$. finmarchicus' population dynamics in the GOM/WSS region are regulated primarily by climate-driven advective changes in the CSWS.

Our findings support the choice of $C$. finmarchicus as a target species for global climate change studies in the Northwest Atlantic (GLOBEC, 1991). Its abundance in the GOM/WSS region is clearly a good indicator of the modal state of the CSWS on interannual to inter- 
decadal time scales. Thus, it provides a useful counterpart to the foraminiferal indicator species that enable us to reconstruct ocean climate changes in this region over longer, centennial to millennial time scales (Keigwin and Jones, 1995; Keigwin and Pickart, 1999). While it appears that $C$. finmarchicus' response to modal shifts in the CSWS may be driven largely by advective processes, other species with self-sustaining populations in the region's shelf ecosystems may be responding instead to changes in the physical environment associated with such modal shifts. Distinguishing between these two different types of species responses to climate change will be critical to reconstructing the past and predicting the future of shelf ecosystems in the Northwest Atlantic and elsewhere.

\section{Acknowledgements}

This paper is contribution \#187 from the US GLOBEC NW Atlantic/Georges Bank Program, with support provided by the NOAA Coastal Ocean Program and the NSF Biological Oceanography Program. This paper was prepared while C. H. Greene was in residence as a sabbatical fellow at the National Center for Ecological Analysis and Synthesis, a Center funded by NSF (Grant \#DEB-0072909) and the University of California, Santa Barbara.

\section{References}

Brown, W.S. and J.D. Irish, 1993: The annual variation of water mass structure in the Gulf of Maine: 1986-1987. J. Mar. Res., 51, 53-107.

Chapman, D.C. and R.C. Beardsley, 1989: On the origin of shelf water in the Middle Atlantic Bight. J. Phys. Oceanogr., 19, 384-391.

Drinkwater, K.F., D.B. Mountain and A. Herman, in press: Variability in the slope water properties off eastern North America and their effects on the adjacent seas. J. Geophys. Res.

Gatien, M.G, 1976: A study in the slope water region south of Halifax. I. Fish. Res. Board Can., 33, 2213-2217.

GLOBEC, 1991: Global Ocean Ecosystem Dynamics: Northwest Atlantic Program. Joint Oceanographic Institutions, Washington, D.C., 76 pp.

Greene, C.H. and A.J. Pershing, 2000: The response of Calanus finmarchicus populations to climate variability in the Northwest Atlantic: Basin-scale forcing associated with the North Atlantic Oscillation (NAO). ICES J. Mar. Sci., 57, 1536-1544.

Hurrell, J.W, 1995: Decadal trends in the North Atlantic Oscillation: regional temperatures and precipitation. Science, 269, 676-679.

Jossi, J.W. and J.R. Goulet, Jr., 1993: Zooplankton trends: U.S. northeast shelf ecosystem and adjacent regions differ from northeast Atlantic and North Sea. ICES J. Mar. Sci., 50, 303-313.
Keigwin, L.D. and G.A. Jones, 1995: The marine record of deglaciation from the continental margin off Nova Scotia. Paleoceanogr., 10, 973-986.

Keigwin, L.D. and R.S. Pickart, 1999: Slope water current over the Laurentian Fan on interannual to millennial time scales. Science, 286, 520-523.

Loder, J.W., J.A. Shore, C.G. Hannah and B.D. Petrie, 2001: Decadal-scale hydrographic and circulation variability in the Scotia-Maine region. Deep Sea Res. II, 48, 3-35.

Longhurst, A., 1998: Ecological Geography of the Sea. Academic Press, San Diego, CA, 398 pp.

Marsh, R., B. Petire, C.R. Weidman, R.R. Dickson, J.W. Loder, C.G. Hannah, K. Frank and K. Drinkwater, 1999: The 1982 tilefish kill-a cold event in shelf waters off the northeastern United States? Fish. Oceanogr., 8, 39-49.

Miller, C.B., D.R. Lynch, F. Carlotti, W.C. Gentleman, and C.V.W. Lewis, 1998: Coupling of an individualbased population dynamic model of Calanus finmarchicus to a circulation model for the Georges Bank region. Fish. Oceanogr., 7, 219-234.

Petrie, B. and K. Drinkwater, 1993: Temperature and salinity variability on the Scotian Shelf and in the Gulf of Maine 1945-1990. J. Geophys. Res., 98, 20,079-20,089.

Pickart, R.S., T.K. McKee, D.J. Torres and S.A. Harrington, 1999: Mean structure and interannual variability of the slopewater system south of Newfoundland. J. Phys. Oceanogr., 29, 2541-2558.

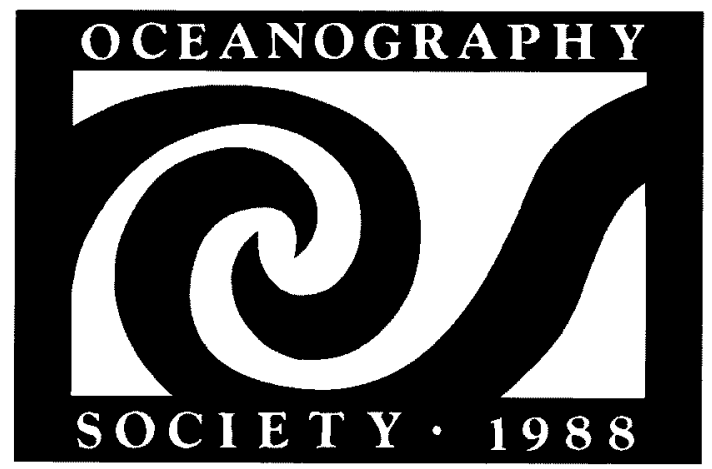

